\title{
Understanding parental self-medication with antibiotics among parents of different nationalities: a cross-sectional study
}

Zhongliang Zhou ${ }^{1 \dagger}$, Dantong Zhao ${ }^{1 \dagger}$, Huarui Zhang ${ }^{2 \dagger}$, Chi Shen ${ }^{1}$, Dan Cao ${ }^{1}$, Guanping Liu', Liang Zhu ${ }^{3 *}$ and Yu Fang ${ }^{4}$

\begin{abstract}
Background: There is an increasing trend on the practices of parental self-medication with antibiotics (PSMA) around world, accelerating the antibiotic abuse. This study aims to examine the nationality differences in the practices of PSMA and knowledge, attitudes and practices (KAP) toward antibiotic use, and understand the practices of PSMA among parents of various nationalities in China.

Methods: A cross-sectional study based on a structured questionnaire survey was conducted in Xi'an, Shaanxi Province, China, from September 2018 to October 2018. A total of 299 respondents participated in. The practices of PSMA (a dichotomous variable) and KAP toward antibiotic use (a continuous variable) served as dependent variables. Participant's nationality was regarded as the independent variable. Binary logistic regression and ordinary least square regression were employed to examine the association between parent's nationality and the practices of PSMA, and KAP toward antibiotic use, respectively.

Results: 121 (40.88\%) Chinese, 100 (33.76\%) other Asians and 75 (25.34\%) Occidentals were included in final analysis, with a sample size of 296 . Chinese were more likely to practice PSMA (OR $=7.070 ; 95 \% \mathrm{Cl} 1.315,38.01)$, with worse knowledge (Coef. $=-0.549 ; 95 \% \mathrm{Cl}-1.021,-0.078$ ), attitudes (Coef. $=-3.069 ; 95 \% \mathrm{Cl}-4.182,-1.956$ ) and practices (Coef. $=-1.976 ; 95 \% \mathrm{Cl}-3.162,-0.790)$ toward antibiotic use, compared to their Occidental counterparts. The main reasons for the practices of PSMA were enough previous medication experience (80.49\%) and same ailments with no need to see a doctor (39.02\%), with common symptoms such as fever (60.98\%) and cough (58.54\%). Purchasing antibiotics at pharmacies (92.08\%) and using leftover antibiotics (26.83\%) were usual approaches.

Conclusions: The study highlights the gaps in the practices of PSMA and KAP toward antibiotic use among parents of different nationalities. The access to obtain antibiotics from pharmacies reflects the pharmacists' unaware of laws on prescription of antibiotics, fierce competition in the pharmacy market, and the government's lax supervision in China. It suggests the need to improve pharmacists' training, enforce current legislations on pharmacy market regarding the sale of antibiotics, and provide practical and effective educational interventions for residents about antibiotic use.
\end{abstract}

\footnotetext{
*Correspondence: liangjulia0317@163.com

'Zhongliang Zhou, Dantong Zhao and Huarui Zhang have contributed

equally to this work and should be considered co-first authors

${ }^{3}$ Department of Health Care Management and Medical Education,

School of Military Preventive Medicine, Air Force Medical University, Xi'an,

China

Full list of author information is available at the end of the article
}

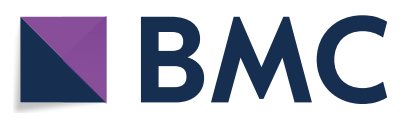

(c) The Author(s) 2021. Open Access This article is licensed under a Creative Commons Attribution 4.0 International License, which permits use, sharing, adaptation, distribution and reproduction in any medium or format, as long as you give appropriate credit to the original author(s) and the source, provide a link to the Creative Commons licence, and indicate if changes were made. The images or other third party material in this article are included in the article's Creative Commons licence, unless indicated otherwise in a credit line to the material. If material is not included in the article's Creative Commons licence and your intended use is not permitted by statutory regulation or exceeds the permitted use, you will need to obtain permission directly from the copyright holder. To view a copy of this licence, visit http://creativecommons.org/licenses/by/4.0/. 
Keywords: Parental self-medication with antibiotics, Nationality, Knowledge, Attitudes, Practices

\section{Background}

Bacterial resistance, a main adverse effect of antibiotic use, is mainly driven by irrational and excessive use of antibiotic in both communities and clinical settings [1]. It is regarded as an important public health concern [2] and one of the biggest threats facing global health [3]. It not only increases disease morbidity and mortality, reduces the efficiency of disease treatment, increases the economic burden of patients, but also makes it easy to generate drug-resistance or multidrugresistance bacteria to further harm health [4]. As the World Health Organization (WHO) points out, "a postantibiotic era-in which common infections and minor injuries can kill everything-far from being an apocalyptic fantasy, is instead a very real possibility for the twenty-first century" [5]. It is great necessary to focus on irrational antibiotic use.

There is an increasing trend on practicing self-medication with antibiotics (SMA) in both developed and developing countries in recent years, which is one of the most dangerous and prevalent inappropriate antibiotic use behaviors [6]. A systematic review conducted in Netherlands reported that the prevalence of SMA ranged from $2 \%$ to $20 \%$ in Europe, with Sweden at $2 \%$, Slovakia $3 \%$, Romania $16 \%$ and Greece at $20 \%$ [7]. Another literature review showed that frequent practices of SMA varied from $23.6 \%$ to $85 \%$ in Asian countries, with $23.6 \%$ in Bhutan, $50 \%$ in Lebanon, $63 \%$ in Kazakhstan, 83.3\% in Vietnam and 85\% in Lao PDR [8]. Moreover, much higher rates of SMA were found in Africa, such as in Ghana (70\%) [9], Kenya (79.9\%) [10], and Nigeria (93.9\%) [11]. Self-medication can be defined as the use of drugs with the aim to treat selfdiagnosed disorders or symptoms, or the intermittent or continued use of a prescribed drug for chronic or recurrent disease and symptoms [12]. Antibiotics for self-medication are usually obtained without a prescription, or by resubmitting old prescriptions to purchase medicines at retail pharmacies, or sharing medicines with relatives or friends, or using leftover medicines stored at home $[6,13,14]$.

In practice, SMA also includes the medication for family members, in particularly, the therapy for children or the old [12]. Previous studies presented that children and adolescents are the most widely users on antibiotics [15], whose medicines are usually purchased by parents themselves [16]. It is commonly known as parental self-medication with antibiotics (PSMA), accelerating the antibiotic abuse [17]. The practices of PSMA are also prevalent around the world, especially in low- and middle-income countries (LMICs) [18, 19]. It was reported that the prevalence of PSMA was $59.4 \%$ in China [20], $42.05 \%$ in Philippines [21], 43\% in Uganda [22] and Nigeria [17], yet this proportion was as low as $22.7 \%$ in Greece [23].

Unlike high-income countries, non-prescribed antibiotics (NPA) (i.e., the use of leftover antibiotics, the use of antibiotics recommended by pharmacy staffs, sharing antibiotics with families or friends [24]) are easy to access in LMICs $[18,25]$, associated with the lack of robust mechanisms of health education and enforcement measures to control the unnecessary and unreasonable use of antibiotics [24, 26]. Moreover, insufficient and inconsistent knowledge and attitudes toward antibiotic use, high expectations on the curative effect of antibiotics, and poor quality of healthcare facilities, are factors driving inappropriate use of antibiotics [24]. Regarding the above gaps in the prevalence of PSMA around the world and various factors influencing the utilization of antibiotics, we therefore hypothesis that the practices of PSMA may differ among parents of different nationalities in China.

As we all know, the irrational or overuse of antibiotics is caused by either health service supplier or demander. The supply side factors mainly include the lack of supervision [27], corruption [28], physicians' profitseeking behavior [29], insufficient knowledge [30] and so on. The demand side reasons are probably due to the public's inadequate knowledge, attitudes and practices (KAP) toward antibiotic use [31-38]. The actual difference among various populations cannot be identified unless controlling the same supplier or the same demander. However, few studies to our knowledge have examined such essential gap. According to the theory of Andersen's Behavioral Model of Health Services Use, health seeking behavior can be influenced by health system environment $[39,40]$. The public is regulated by unified health policies when residing in the same city. This study therefore selected parents of different nationalities living in the same city, on behalf of different health service demanders but the same supplier.

In the current study, we aim to (1) explore the association between parent's nationality and the practices of PSMA; (2) examine the nationality differences in KAP toward antibiotic use; (3) understand the practices of PSMA among parents of various nationalities living in China. 


\section{Methods}

\section{Study design and setting}

This was a cross-sectional study conducted in Xi'an $\mathrm{Hi}$-Tech International School, International Department (XHISID), Shaanxi Province, China, for a period of 2 months from September 2018 to October 2018. XHISID was founded in 2003. It is the first International Baccalaureate (IB) World School authorized by the IB Organization in the northwest region of China, also a key international education program supported by the Hi-Tech Zone Administrative Committee of Xi'an, Shaanxi. XHISID has more than 300 students from about 15 countries around the world. It is a 15-year consistent school. School offers the IB-Primary Years Programme, IB-Middle Years Programme and the Diploma Programme continuum from kindergarten to high school. It is the only SAT and AP test center authorized by the American College Board in the northwestern region of China. XHISID provides a non-profit education focused on enabling confident, open-minded global citizens through life-long learning and a sense of community.

\section{Sampling}

The sample size was calculated using Raosoft [41], an online sample size calculator frequently applied in studies [42-44]. We assumed the prevalence of PAMA to be $30 \%$ among various populations (referring to previous studies conducted in various regions) and determined the confidence interval at $95 \%$ with the margin of error $5 \%$. The population size was assumed to be 20,000 as suggested by the Raosoft, since there was no official statistics on international populations in Xi'an and the sample size doesn't change much for populations larger than 20,000 [41]. The required sample size estimated for the survey was 318 . A convenience sample of 350 participates were included in this study to account for a $10 \%$ non-response rate.

\section{Participants and data collection}

The survey was conducted at classrooms after parents meeting. Participants were eligible to be included if they: (1) being a parent whose child was studying at XHISID; (2) having no hearing or visual disorder; (3) being literate; (4) volunteering to participate in. An introduction to study purpose, significance and privacy safety was informed to participants by our investigators before the investigation. Respondents were required to self-complete questionnaire with their informed consent. Finished questionnaires were collected by the investigators on the spot. A total of 299 individuals participated in the investigation and accomplished questionnaire.

\section{Development of questionnaire}

The questionnaire was developed by reviewing applicable comparable studies [18, 33, 45-49] and consultation with pharmacy experts. Face and content validation of the questionnaire was performed by pharmacy professionals and academics. Feedback was collected to improve the questionnaire presentation, clarity, logicality and congruency of meaning. The questionnaire was originally developed in English (see Additional file 1), which was then translated into Chinese (see Additional file 2), for non-Chinese and Chinese participates, respectively. A pilot study was carried out to address any ambiguity in the questions and the acceptability to the participants among 30 respondents. The questionnaire consisted of three main parts: (1) the socio-economic characteristics of parents and children; (2) the practices of PSMA; (3) the assessment of KAP toward antibiotic use. Cronbach's alpha was 0.85 for the part of KAP toward antibiotic use.

\section{Measurement}

296 individuals were eventually analyzed excluding the missing values. PSMA served as a dependent variable in this study, measured by question, "Did you self-medicate your child with antibiotics in the past 6 months", with an answer of "No" or "Yes", coding 0 and 1 . Another dependent variable was KAP toward antibiotic use. Antibiotic knowledge was composed of 6 questions, with an answer of "True", "False" and "Not sure". We classified the answer into "Wrong" (including incorrect answers and "Not sure") and "Right" (correct answers), coding 1 and 2. The sum score ranged from 6 to 12, with higher score indicating better antibiotic knowledge. Antibiotic attitudes consisted of 14 items. Each item is answered on a five-point Likert scale ("Totally agree" to "Totally disagree"), coding from 1 to 5 . A total scale score was computed by summing item scores, with a range of 5 to 25 . Higher scores indicated better antibiotic attitudes. Practices of antibiotic use were measured by 12 items with a five-point Likert response ("Always" to "Never"), coding from 1 to 5 . Item scores were summed and converted to a scale ranging from 6 to 30, with higher scores presenting better antibiotic behaviors. The total antibiotic score was the sum of the above scales, ranging from 17 to 67, where higher values indicated better antibiotic perceptions.

Parent's nationality was an independent variable, with a category of Chinese, other Asian and Occidental. Control variables included parent's gender (male, female; a dichotomous variable), age (27-52 years; a continuous variable), education level (below Bachelor, Bachelor, Master and above; a categorical variable) and income (<0.5 million, 0.5-1 million, $>1$ million; a categorical variable), having medical staff or not in family (no, yes; a 
dichotomous variable), child's age ( $2-19$ years; a continuous variable) and gender (male, female; a dichotomous variable), the only child or not (no, yes; a dichotomous variable) and having medical insurance or not (no, yes; a dichotomous variable). In addition, total antibiotic score (17-67; a continuous variable) was controlled when examining the association between parent's nationality and the practices of PSMA.

\section{Statistical analysis}

The data was entered into a database using the Epidata 3.1, and transferred to Stata statistical software (version15.0; StataCorp LP, College Station, Texas) for all analysis. One-way ANOVA and Kruskal-Wallis test were used to compare KAP toward antibiotic use among parents of different nationalities. The association between parent's nationality and the practices of PSMA was examined using the binary logistic regression model adjusted for socio-economic characteristics of parents and children, and antibiotic score. Ordinary least square (OLS) regression controlling for socio-economic characteristics of parents and children was employed to examine the association between parent's nationality and KAP toward antibiotic use. $P$ value was at the significance level $\alpha=0.05$.

\section{Results}

The response rate was $84.57 \%$. As Table 1 is shown, 121 (40.88\%) Chinese parents, 100 (33.78\%) other Asian parents and 75 (25.34\%) Occidental parents comprised the study sample. The proportion of female was $84.30 \%$, $73.00 \%$ and $37.33 \%$ among parents of three nationalities, respectively. The average age of the respondents was $37.96(\mathrm{SD}=5.45)$ years, $40.71(\mathrm{SD}=3.63)$ years and 39.44 $(\mathrm{SD}=4.63)$ years. Minority of the respondents' families

Table 1 General characteristics of parents and children

\begin{tabular}{|c|c|c|c|c|c|c|}
\hline \multirow[t]{2}{*}{ Variables } & \multicolumn{2}{|l|}{$\begin{array}{l}\text { Chinese } \\
(N=121)\end{array}$} & \multicolumn{2}{|l|}{$\begin{array}{l}\text { Other Asian } \\
(\mathrm{N}=100)\end{array}$} & \multicolumn{2}{|l|}{$\begin{array}{l}\text { Occidental } \\
(\mathrm{N}=75)\end{array}$} \\
\hline & $\mathbf{N}$ & $\%$ & $\mathbf{N}$ & $\%$ & $\mathrm{~N}$ & $\%$ \\
\hline \multicolumn{7}{|l|}{ Parents } \\
\hline \multicolumn{7}{|l|}{ Gender } \\
\hline Male & 19 & 15.70 & 27 & 27.00 & 47 & 62.67 \\
\hline Female & 102 & 84.30 & 73 & 73.00 & 28 & 37.33 \\
\hline \multicolumn{7}{|l|}{ Age, years } \\
\hline Mean (SD) & $37.96(5.45)$ & & $40.71(3.63)$ & & $39.44(4.63)$ & \\
\hline \multicolumn{7}{|l|}{ Education level } \\
\hline Below bachelor & 22 & 18.19 & 29 & 29.00 & 4 & 5.33 \\
\hline Bachelor & 55 & 45.45 & 52 & 52.00 & 26 & 34.67 \\
\hline Master and above & 44 & 36.36 & 19 & 19.00 & 45 & 60.00 \\
\hline \multicolumn{7}{|l|}{ Medical staff in family } \\
\hline No & 96 & 79.34 & 86 & 86.00 & 55 & 73.33 \\
\hline Yes & 25 & 20.66 & 14 & 14.00 & 20 & 26.67 \\
\hline \multicolumn{7}{|l|}{ Income, million, CNY } \\
\hline$<0.5$ & 62 & 51.24 & 37 & 37.00 & 67 & 89.33 \\
\hline $0.5-1$ & 30 & 24.79 & 46 & 46.00 & 5 & 6.67 \\
\hline$>1$ & 29 & 23.97 & 17 & 17.00 & 3 & 4.00 \\
\hline \multicolumn{7}{|l|}{ Children } \\
\hline \multicolumn{7}{|l|}{ Gender } \\
\hline Male & 61 & 50.41 & 40 & 40.00 & 53 & 70.67 \\
\hline Female & 60 & 49.59 & 60 & 60.00 & 22 & 29.33 \\
\hline \multicolumn{7}{|l|}{ Age, years } \\
\hline Mean (SD) & $7.46(3.73)$ & & $10.07(3.85)$ & & $8.89(5.42)$ & \\
\hline \multicolumn{7}{|l|}{ Medical insurance } \\
\hline No & 31 & 25.62 & 21 & 21.00 & 12 & 16.00 \\
\hline Yes & 90 & 74.38 & 79 & 79.00 & 63 & 84.00 \\
\hline
\end{tabular}

Assessed from full sample, $\mathrm{N}=296$

$\mathrm{SD}=$ standard deviation 
Table 2 Description of the practices of parental self-medication with antibiotics (PSMA)

\begin{tabular}{|c|c|c|}
\hline Variables & Mean/N & $\mathrm{SD} / \%$ \\
\hline Medication & Mean & $S D$ \\
\hline Frequency in the past 6 months, times & 1.44 & 0.63 \\
\hline Duration, days & 3.46 & 1.12 \\
\hline Reasons (Multi-choice) & N & $\%$ \\
\hline Same ailments with no need to see a doctor & 16 & 39.02 \\
\hline Enough previous medication experience & 33 & 80.49 \\
\hline Long waiting time in the clinics & 4 & 9.76 \\
\hline Convenience & 1 & 2.44 \\
\hline Expensive consultation fees & 1 & 2.44 \\
\hline Symptoms (Multi-choice) & N & $\%$ \\
\hline Cold (Runny nose or nasal congestion) & 7 & 17.07 \\
\hline Cough & 24 & 58.54 \\
\hline Fever & 25 & 60.98 \\
\hline Sore throat & 14 & 34.15 \\
\hline Bronchitis & 18 & 43.90 \\
\hline Body ache & 3 & 7.32 \\
\hline Headache & 3 & 7.32 \\
\hline Emesis & 0 & 0.00 \\
\hline Diarrhea & 2 & 4.88 \\
\hline Otitis media & 4 & 9.76 \\
\hline Skin trauma & 0 & 0.00 \\
\hline Sources of antibiotic information (Multi-choice) & $N$ & $\%$ \\
\hline Previous medication experience & 33 & 80.49 \\
\hline Suggestions from relatives and friends & 9 & 21.95 \\
\hline Recommendations of pharmacy staffs & 8 & 19.51 \\
\hline Internet knowledge & 2 & 4.88 \\
\hline Drug instruction & 5 & 12.20 \\
\hline Approaches (Multi-choice) & N & $\%$ \\
\hline Leftover of previous antibiotics & 11 & 26.83 \\
\hline Purchasing antibiotics at pharmacies & 38 & 92.08 \\
\hline Given by others & 1 & 2.44 \\
\hline
\end{tabular}

Assessed from individuals with the practices of PSMA, N=41

$\mathrm{SD}=$ standard deviation had medical staffs and majority of children had been covered by medical insurance.

It was found that $13.85 \%$ of the respondents practiced PSMA in the past 6 months. The prevalence of PSMA among Chinese was higher than that among other Asians and Occidentals $(28.10 \%, 5.00 \%$ and $2.67 \%$ for Chinese, other Asians and Occidentals, respectively, $P<0.001)$.

As Table 2 is presented, respondents practiced an average of 1.44 $(\mathrm{SD}=0.63)$ times PSMA in the past 6 months, with a duration of $3.46(\mathrm{SD}=1.12)$ days. The main reasons for the practices of PSMA were enough previous medication experience $(80.49 \%)$ and the same ailments with no need to see a doctor (39.02\%), with the common symptoms such as fever (60.98\%), cough (58.54\%), bronchitis $(43.90 \%)$, sore throat $(34.15 \%)$ and cold $(17.07 \%)$. Sources of antibiotic information were mainly previous medication experience (80.49\%), suggestions from relatives and friends (21.95\%) and recommendations of pharmacy staffs (19.51\%). Purchasing antibiotics at pharmacies $(92.08 \%)$ and using leftover antibiotics (26.83\%) were usual approaches to access to antibiotics for PSMA.

KAP toward antibiotic use among parents of different nationalities are showed in Table 3. Occidental parents performed better than their Chinese counterparts, followed by other Asians (10.07 vs. 9.65 vs. 8.98 regarding antibiotic knowledge, 20.53 vs. 18.46 vs. 17.02 regarding antibiotic attitudes, 28.23 vs. 26.07 vs. 22.80 regarding antibiotic behaviors among Occidentals, Chinese and other Asians, respectively. $P<0.001)$. With regard to the perception of antibiotic use, Occidental parents still performed better than Chinese, followed by other Asians (58.83 vs. 54.18 vs. $48.80, P<0.001$ ).

The results of regression analyses examining the association between parent's nationality and the practices of PSMA, and the association between nationality and KAP toward antibiotic use are conducted and presented in Table 4. It was found that Chinese were more likely to practice PSMA (OR=7.070; 95\% CI 1.315, 38.01), and

Table 3 knowledge, attitudes and practices (KAP) toward antibiotic use among parents of different nationalities

\begin{tabular}{|c|c|c|c|c|c|c|c|c|}
\hline \multirow[t]{2}{*}{ Variables } & \multicolumn{2}{|c|}{$\begin{array}{l}\text { Chinese } \\
(N=121)\end{array}$} & \multicolumn{2}{|c|}{$\begin{array}{l}\text { Other Asian } \\
(\mathrm{N}=100)\end{array}$} & \multicolumn{2}{|c|}{$\begin{array}{l}\text { Occidental } \\
(\mathrm{N}=75)\end{array}$} & \multirow[t]{2}{*}{$F / X^{2}$} & \multirow[t]{2}{*}{$P$ value } \\
\hline & Mean & SD & Mean & SD & Mean & SD & & \\
\hline Knowledge score ${ }^{a}$ & 9.65 & 1.55 & 8.98 & 1.29 & 10.07 & 1.49 & 12.77 & $<0.001$ \\
\hline Attitude score ${ }^{\mathrm{a}}$ & 18.46 & 3.54 & 17.02 & 3.42 & 20.53 & 3.74 & 20.96 & $<0.001$ \\
\hline Practice score ${ }^{b}$ & 26.07 & 4.03 & 22.80 & 3.99 & 28.23 & 2.30 & 85.00 & $<0.001$ \\
\hline Antibiotic score ${ }^{b}$ & 54.18 & 7.32 & 48.80 & 6.80 & 58.83 & 6.18 & 75.32 & $<0.001$ \\
\hline
\end{tabular}

Antibiotic score was computed by summing antibiotic knowledge, attitude and practice score

Assessed from full sample, $\mathrm{N}=296$

$\mathrm{SD}=$ standard deviation

a One-way ANOVA

${ }^{\mathrm{b}}$ Kruskal-Wallis test 
Table 4 The association between parent's nationality and 1) the practices of PSMA, 2) knowledge, attitudes, and practices toward antibiotic use

\begin{tabular}{|c|c|c|c|c|}
\hline Variables & $\begin{array}{l}\text { PSMA }^{a} \\
\text { OR } \\
(95 \% \mathrm{CI})\end{array}$ & $\begin{array}{l}\text { Knowledge } \\
\text { Coef } \\
(95 \% \mathrm{Cl})\end{array}$ & $\begin{array}{l}\text { Attitudes } \\
\text { Coef } \\
(95 \% \mathrm{Cl})\end{array}$ & $\begin{array}{l}\text { Practices }^{b} \\
\text { Coef } \\
(95 \% \mathrm{Cl})\end{array}$ \\
\hline \multicolumn{5}{|l|}{ Nationality of parents } \\
\hline Occidental & Ref & & & \\
\hline Chinese & $\begin{array}{l}7.070^{*} \\
(1.315-38.010)\end{array}$ & $\begin{array}{l}-0.549^{*} \\
(-1.021--0.078)\end{array}$ & $\begin{array}{l}-3.069^{* * *} \\
(-4.182--1.956)\end{array}$ & $\begin{array}{l}-1.976^{* *} \\
(-3.162--0.790)\end{array}$ \\
\hline Other Asian & $\begin{array}{l}0.500 \\
(0.059-4.266)\end{array}$ & $\begin{array}{l}-0.974^{* * *} \\
(-1.484--0.463)\end{array}$ & $\begin{array}{l}-4.088^{* * *} \\
(-5.294--2.882)\end{array}$ & $\begin{array}{l}-4.992^{* * *} \\
(-6.276--3.707)\end{array}$ \\
\hline \multicolumn{5}{|l|}{ Gender of parents } \\
\hline Male & Ref & & & \\
\hline Female & $\begin{array}{l}1.191 \\
(0.339-4.183)\end{array}$ & $\begin{array}{l}-0.110 \\
(-0.502-0.281)\end{array}$ & $\begin{array}{l}2.908^{* * *} \\
(1.983-3.833)\end{array}$ & $\begin{array}{l}0.991^{*} \\
(0.005-1.977)\end{array}$ \\
\hline Age of parents, years & $\begin{array}{l}0.971 \\
(0.874-1.079)\end{array}$ & $\begin{array}{l}-0.067^{* *} \\
(-0.110--0.024)\end{array}$ & $\begin{array}{l}-0.066 \\
(-0.168-0.036)\end{array}$ & $\begin{array}{l}-0.170^{* *} \\
(-0.279--0.061)\end{array}$ \\
\hline \multicolumn{5}{|l|}{ Education level of parents } \\
\hline Below bachelor & Ref & & & \\
\hline Bachelor & $\begin{array}{l}0.611 \\
(0.209-1.788)\end{array}$ & $\begin{array}{l}-0.478^{*} \\
(-0.932--0.024)\end{array}$ & $\begin{array}{l}0.528 \\
(-0.544-1.600)\end{array}$ & $\begin{array}{l}1.296^{*} \\
(0.153-2.438)\end{array}$ \\
\hline Master and above & $\begin{array}{l}0.495 \\
(0.148-1.656)\end{array}$ & $\begin{array}{l}-0.259 \\
(-0.749-0.230)\end{array}$ & $\begin{array}{l}0.529 \\
(-0.627-1.685)\end{array}$ & $\begin{array}{l}2.265^{* * *} \\
(1.033-3.496)\end{array}$ \\
\hline \multicolumn{5}{|l|}{ Income, million, CNY } \\
\hline$<0.5$ & Ref & & & \\
\hline $0.5-1$ & $\begin{array}{l}3.568^{*} \\
(1.312-9.702)\end{array}$ & $\begin{array}{l}-0.028 \\
(-0.434-0.378)\end{array}$ & $\begin{array}{l}-0.685 \\
(-1.644-0.275)\end{array}$ & $\begin{array}{l}-0.199 \\
(-1.222-0.823)\end{array}$ \\
\hline$>1$ & $\begin{array}{l}0.661 \\
(0.201-2.178)\end{array}$ & $\begin{array}{l}0.304 \\
(-0.173-0.782)\end{array}$ & $\begin{array}{l}-0.736 \\
(-1.865-0.392)\end{array}$ & $\begin{array}{l}0.251 \\
(-0.951-1.453)\end{array}$ \\
\hline \multicolumn{5}{|c|}{ Having medical staff or not in family } \\
\hline No & Ref & & & \\
\hline Yes & $\begin{array}{l}2.764^{*} \\
(1.080-7.077)\end{array}$ & $\begin{array}{l}0.717^{* * *} \\
(0.307-1.126)\end{array}$ & $\begin{array}{l}0.558 \\
(-0.409-1.526)\end{array}$ & $\begin{array}{l}0.636 \\
(-0.395-1.667)\end{array}$ \\
\hline \multicolumn{5}{|l|}{ Gender of children } \\
\hline Male & Ref & & & \\
\hline Female & $\begin{array}{l}0.734 \\
(0.318-1.697)\end{array}$ & $\begin{array}{l}0.145 \\
(-0.185-0.476)\end{array}$ & $\begin{array}{l}0.131 \\
(-0.648-0.911)\end{array}$ & $\begin{array}{l}-0.511 \\
(-1.342-0.320)\end{array}$ \\
\hline Age of children, years & $\begin{array}{l}0.856^{*} \\
(0.742-0.988)\end{array}$ & $\begin{array}{l}-0.041 \\
(-0.087-0.010)\end{array}$ & $\begin{array}{l}-0.098 \\
(-0.206-0.010)\end{array}$ & $\begin{array}{l}0.0521 \\
(-0.063-0.167)\end{array}$ \\
\hline \multicolumn{5}{|l|}{ The only child or not } \\
\hline No & Ref & & & \\
\hline Yes & $\begin{array}{l}1.042 \\
(0.456-2.383)\end{array}$ & $\begin{array}{l}-0.219 \\
(-0.570-0.132)\end{array}$ & $\begin{array}{l}-1.331^{* *} \\
(-2.159--0.502)\end{array}$ & $\begin{array}{l}-1.732^{* * *} \\
(-2.615--0.849)\end{array}$ \\
\hline \multicolumn{5}{|c|}{ Having medical insurance or not } \\
\hline No & Ref & & & \\
\hline Yes & $\begin{array}{l}0.364^{*} \\
(0.141-0.943)\end{array}$ & $\begin{array}{l}-0.236 \\
(-0.638-0.167)\end{array}$ & $\begin{array}{l}-0.103 \\
(-1.053-0.848)\end{array}$ & $\begin{array}{l}-0.476 \\
(-1.489-0.536)\end{array}$ \\
\hline Antibiotic score & $\begin{array}{l}0.923^{*} \\
(0.865-0.984)\end{array}$ & & & \\
\hline
\end{tabular}

Assessed from full sample, $\mathrm{N}=296$

Antibiotic score was computed by summing antibiotic knowledge, attitude and practice score

$\mathrm{OR}=$ odds ratio, Coef. $=$ coefficient, $95 \% \mathrm{Cl}=95 \%$ confidence interval 
Table 4 (continued)

\footnotetext{
a Binary logistic regression

${ }^{\mathrm{b}}$ Ordinary least square regression

***P $P<0.001,{ }^{* *} P<0.01,{ }^{*} P<0.05$
}

performed worse in knowledge (Coef. $=-0.549 ; 95 \% \mathrm{CI}$ $-1.021,-0.078)$, attitudes (Coef. $=-3.069 ; 95 \%$ CI $-4.182,-1.956)$ and practices (Coef. $=-1.976$; 95\% CI $-3.162,-0.790)$ toward antibiotic use, compared to their Occidental counterparts.

\section{Discussion}

To our knowledge, this is the first study to understand the practices of PSMA, and KAP toward antibiotic use among parents of various nationalities under Chinese health system. Our results demonstrated that: (1) Chinese were more likely to practice PSMA, and performed worse KAP toward antibiotic use, compared to their Occidental counterparts; (2) the practices of PSMA occurred for symptoms such as fever and cough, mainly because of previous medication experience and the same ailments with no need to see a doctor; (3) the common sources of antibiotic information included previous medication experience, and the recommendations from relatives, friends and pharmacy personnel; (4) antibiotics for self-medication were often obtained from pharmacies and leftover of previous medication.

It is well known that unnecessary and irrational use of antibiotics is a major cause of bacterial resistance [50], which is accelerated by the prevalent fact of PSMA. Previous studies showed that the rate of the practices of PSMA was high in China [51], ranging from $32.20 \%$ to $62 \%[18,20,48,52]$. However, it was only $4.0 \%$ in urban U.S., $12.1 \%$ in suburban U.S. [53], and $22.7 \%$ in the Greece [23]. As for other Asian countries, it was 43.9\%, $39.2 \%$ and 29.8\% in Saudi Arabia [54], Jordan [55] and Vietnam [56], respectively. It's worth noting that nationality was associated with the practices of PSMA in this study, showing that Chinese parents were more likely to self-medicate with antibiotics for children than Occidental parents, the same as the above findings conducted in separate countries $[18,20,23,48,52,53]$. However, the essential difference in the practices of PSMA among populations of various nationalities is revealed in this study, as the legislations and healthcare services provider were unbiased for residents (under Chinese health system), which makes it more convincing than directly comparing the practices of PSMA among various countries or regions.

The practices of PSMA difference among parents of various nationalities could be explained by KAP toward antibiotic use that parents performed. The finding outlined significant gap in KAP among parents of different nationalities, indicating that Occidental parents performed better than Chinese, which is less confounded by healthcare provider factors as they lived in the same city under the same health system. Several studies state that the control of irrational use of antibiotics is mainly dominated by regulation of physician prescription and correct KAP toward antibiotic use [57, 58]. Plenty of campaigns educating the public about the appropriate use of antibiotics were successfully held at a national or regional level in many high-income countries from 1990 to 2007, including Australia, Canada, France, the UK, New Zealand and so on [59]. China has also demonstrated a series of educational activities on rational use of antibiotics since 2010 [60]. Considering educational campaigns about the appropriate use of antibiotics in European and American countries were carried out earlier than China and have already got excellent achievements [59], Occidental parents naturally performed much better KAP toward antibiotic use. It suggests that intensive educational interventions that provide more and accurate knowledge about the rational use of antibiotics for residents at community level are urgently needed in China.

Regarding the antibiotics for self-medication, previous studies showed that they were usually obtained from over-the-counter purchases at retail pharmacies and leftover medications from previous prescriptions [61, 62], in line with our findings. Actually, despite being prescription-only medicines (POM), antibiotics are available without a valid prescription in many LMICs [26], with an estimation of over $50 \%$ [6]. In China, a recent study conducted in 13 provinces indicated that NPA could be purchased at $83.6 \%$ pharmacies, and only $11.9 \%$ pharmacies asked the consumers if they had a prescription [62]. This raises concern about the role of pharmacies in the misuse of antibiotics, given that the Chinese government has officially banned non-prescription dispensing of antibiotics since 2004 [63]. It reveals the fierce competition in the pharmacy market, the poor inspection of pharmacies, the fragile law enforcement capabilities, and the pharmacists' unaware of local laws and regulations on prescription of antibiotics $[64,65]$. Moreover, what the individuals practicing PSMA may not realize is that using NPA exposes their children to various health risks, increasing the healthcare costs and the burden of resistant infections [66]. Therefore, educational interventions should target not only residents at community level, but also pharmacists in pharmacies at society level [67], combined with a series of strategies to improve pharmacists' training, 
enforce current legislations focusing on frequent supervisions, inspections and penalties of all pharmacies in China.

Nowadays, driven by the fact of aggressive marketing strategies and high expectations for antibiotics, antibiotics are often mistaken used to treat self-diagnosed nonbacterial diseases and viral infections. Children suffering from the Upper Respiratory Tract Infection (URI) with symptoms of fever, cold, cough and sore throat are more likely to be self-medicated with antibiotics [68-70]. Furthermore, the evidences and our findings indicate that the practices of PSMA are attributable to the same ailments with no need to see a doctor [46], the long waiting time in the clinics [71], storing antibiotics at home [48] and enough previous medication experience [72]. Therefore, healthcare providers need to take measures to provide convenience for the patients and reduce the waiting time at healthcare facilities as far as possible, thus enabling the access to healthcare facilities and the guidance of wise and rational use of antibiotics.

\section{Limitations}

We acknowledge several limitations of this study that need to be addressed in future studies. Firstly, this study is limited in the sample population conducted in an International School, resulting in inadequate sample size. Participates are much richer and better educated than general populations because of the convenience sampling, which leads to the selection bias and cannot be well generalized to the whole population of different nationalities. Secondly, self-administered questionnaire can be subject to social-desirability bias, leading to untrue feelings and practices. Thirdly, participates' medical insurances are not identified in this study. Different type of medical insurance coverage may lead to different health seeking behavior and the practices of PSMA. Fourthly, local Chinese may be more familiar with health system and easier to get access to antibiotics compared to non-Chinese, although they both live in the same city for a long time. Fifthly, the lack information of grandparents of the children may underestimate the practices of PSMA, since grandparents are also the main caregivers for children [73]. In addition, no data are available to understand the practices of PSMA among African participates in this study, thus the findings are incomplete and defective. Considering the high prevalence of SMA [9-11, 66] and the scarce literatures on the practices of PSMA in Africa $[17,22]$, future study understanding the practices of PSMA and KAP toward antibiotic use among African are need. Therefore, the findings in this study need to be cautiously explained and extrapolated. Despite the aforementioned limitations, findings from the current study supplement and improve the existing literatures on the practices of PSMA and KAP toward antibiotic use, against the background of different demanders but the same health services supplier. This study provides crucial empirical evidence regarding the nationality differences in the practices of PSMA and KAP toward antibiotic use, with practical implications for the improvement of regulations and the promotion of health education on antibiotics for the public in China.

\section{Conclusions}

The study highlights the gaps in the practices of PSMA and KAP toward antibiotic use among parents of various nationalities, indicating that Chinese are more likely to practice PSMA, with worse KAP toward antibiotic use, compared to their Occidental counterparts. The access to obtain antibiotics from pharmacies reflects the pharmacists' unaware of laws and regulations on prescription of antibiotics, fierce competition in the pharmacy market and the government's lax supervision in China. These findings suggest the need for Chinese health sector and government not only to strengthen the supervision and regulation on pharmacy market regarding the sale of antibiotics, but also improve pharmacists' training, and provide practical and effective educational interventions for the public about rational use of antibiotics via doctorpatient communication, brochures, poster, lectures and Internet, to discourage the practices of PSMA.

\section{Abbreviations}

WHO: World Health Organization; NPA: Non-prescribed antibiotics; SMA: Selfmedication with antibiotics; PSMA: Parental self-medication with antibiotics; KAP: Knowledge, attitudes and practices; LMICs: Low- and middle- income countries; XHISID: Xi'an Hi-Tech International School, International Department; IB: International Baccalaureate; OLS: Ordinary least square; POM: Prescription-only medicines; URI: Upper Respiratory Tract Infection.

\section{Supplementary Information}

The online version contains supplementary material available at https://doi. org/10.1186/s41256-021-00226-y.

Additional file 1: Questionnaire of parental self-medication with antibiotics among parents of different nationalities (English Version).

Additional file 2: Questionnaire of parental self-medication with antibiotics among parents of different nationalities (Chinese Version).

\section{Acknowledgements}

The authors would like to thank school personnel for assisting in organizing and coordinating. The authors appreciate respondents' active participation.

\section{Authors' contributions}

$Z Z, D Z, Y F$ and LZ contributed to the overall design and conceptualization. DZ contributed to data analysis, interpretation and the original draft writing. $\mathrm{ZZ}, \mathrm{DZ}$ and $\mathrm{HZ}$ contributed to the editing and revising of the manuscript. $\mathrm{HZ}$, CS, DC and GL collected and cleaned the data. CS provided statistical analysis 
guidance. All authors reviewed the manuscript and approved the final manuscript for submission.

\section{Funding}

This study was funded by National Natural Science Foundation of China (71874137) and Shaanxi Social Science Foundation (2017S024).

\section{Availability of data and materials}

The datasets used and/or analyzed during the current study are available from the corresponding author on reasonable request.

\section{Declarations}

\section{Ethics approval and consent to participate}

Ethical approval for this project was granted by the Ethics Committee of Xi'an Jiaotong University Health Science Center Biomedicine. Informed consents approved by the ethics committee were obtained from all participants before we investigators told them the survey purpose and privacy safety printed at the top of the questionnaire. All methods were performed in accordance with the relevant guidelines and regulations.

\section{Consent for publication}

Not applicable.

\section{Competing interests}

The authors declare that they have no competing interests.

\section{Author details}

${ }^{1}$ School of Public Policy and Administration, Xi'an Jiaotong University, Xi'an, China. ${ }^{2}$ Xi'an Lianhu District Huoshaobei Clinic, Xi'an, China. ${ }^{3}$ Department of Health Care Management and Medical Education, School of Military Preventive Medicine, Air Force Medical University, Xi'an, China. ${ }^{4}$ School of Pharmacy, Health Science Center, Xi'an Jiaotong University, Xi'an, China.

\section{Received: 30 June 2021 Accepted: 14 October 2021}

\section{Published online: 25 October 2021}

\section{References}

1. Spencer JR, Milburn EK, Chukwuma U. Correlation between antimicrobial resistance in Escherichia coli infections in hospitalized patients and rates of inpatient prescriptions for selected antimicrobial agents, Department of Defense hospitals, 2010-2014. MSMR. 2016;23(3):6-10.

2. Eystathios S, Panagiotis M, Athanasia P, Aristofanis G, George M, Christos $P$, et al. Self-medication with antibiotics in rural population in Greece: a cross-sectional multicenter study. BMC Fam Pract. 2010;11(1):58.

3. Laxminarayan R, Duse A, Wattal C, Zaidi AKM, Wertheim HFL, Sumpradit $\mathrm{N}$, et al. Antibiotic resistance-the need for global solutions. Lancet Infect Dis. 2013;13(12):1057-98.

4. Eliopoulos GM, Cosgrove SE, Carmeli Y. The impact of antimicrobial resistance on health and economic outcomes. Clin Infect Dis. 2003;36(11):1433-7.

5. WHO. Antimicrobial resistance: global report on surveillance. Geneva: WHO; 2014.

6. Morgan DDJ, Okeke IN, Laxminarayan R, Perencevich EN, Weisenberg S. Non-prescription antimicrobial use worldwide: a systematic review. Lancet Infect Dis. 2011;11(9):692-701.

7. Dominique L, John P, Francois S, van Liset D. Determinants of selfmedication with antibiotics in European and Anglo-Saxon countries: a systematic review of the literature. Front Public Health. 2018;6:370.

8. Widowati I, Budayanti N, Januraga PP, Duarsa D. Self-medication and self-treatment with short-term antibiotics in Asian countries: a literature review. Pharm Educ. 2021;21(2):152-62.

9. Torres NF, Solomon VP, Middleton LE. Patterns of self-medication with antibiotics in Maputo City: a qualitative study. Antimicrob Resist Infect Control. 2019;8(1):161.

10. Owour I, Alwar J, Oyugi H. Perceptions influencing self medication with antibiotics and/or antimalarials among the households in Nyalenda
B Sub-Location, Kisumu County, Kenya. Am J Public Health Res. 2015;3(3):116-21.

11. Israel E, Emmanuel E, Sylvester E, Chukuma E. Self-medication with antibiotics amongst civil servants in Uyo, Southern Nigeria. J Adv Med Pharm Sci. 2015;2(3):89-97.

12. Whittaker A. Guidelines for the identification and management of substance use and substance use disorders in pregnancy. Drug Alcohol Rev. 2015;34(3):340-1.

13. WHO. WHO guidelines for the regulatory assessment of medicinal products for use in self-medication: general information. WHO Drug Inf. 2000;14(1):18-26.

14. Ocan M, Obuku EA, Bwanga F, Akena D, Richard S, Ogwal-Okeng J, et al. Household antimicrobial self-medication: a systematic review and metaanalysis of the burden, risk factors and outcomes in developing countries. BMC Public Health. 2015;15(1):742.

15. Kan Q, Wen J, Liu X, Li Z. Inappropriate use of antibiotics in children in China. The Lancet. 2016;387(10025):1273-4.

16. Liao RY. Investigation on the impact of parents' cognitive level of antibiotics on selfdirected use of antibiotics in pupils (in Chinese). Pract Prev Med. 2013:20(1):42-5.

17. Oshikoya KA, Njokanma OF, Bello JA, Ayorinde EO. Family self-medication for children in an urban area of Nigeria. Paediatr Perinat Drug Therapy. 2007;8(3):124-30.

18. Xu J, Wang X, Sun KS, Lin L, Zhou X. Parental self-medication with antibiotics for children promotes antibiotic over-prescribing in clinical settings in China. Antimicrob Resist Infect Control. 2020;9(1):150.

19. Fink G, D'Acremont V, Leslie HH, Cohen J. Antibiotic exposure among children younger than 5 years in low-income and middle-income countries: a cross-sectional study of nationally representative facility-based and household-based surveys. Lancet Infect Dis. 2020;20(2):179-87.

20. Bi P, Tong S, Parton KA. Family self-medication and antibiotics abuse for children and juveniles in a Chinese city. Soc Sci Med. 2000;50(10):1445-50.

21. Bulario JS, Cruz ILP, Pilapil MC, Gutierrez MM. Factors associated with parental self-medication of antibiotics in Health Centers of Manila. KnE Soc Sci. 2018;3(6):891-910.

22. Kibuule D, Kagoya HR, Godman B. Antibiotic use in acute respiratory infections in under-fives in Uganda: findings and implications. Expert Rev Anti Infect Ther. 2016;14(9):863-72.

23. Mitsi G, Jelastopulu E, Basiaris H, Skoutelis A, Gogos C. Patterns of antibiotic use among adults and parents in the community: a questionnairebased survey in a Greek urban population. Int J Antimicrob Agents. 2005;25(5):439-43.

24. Torres NF, Chibi B, Kuupiel D, Solomon VP, Mashamba-Thompson TP, Middleton LE. The use of non-prescribed antibiotics; prevalence estimates in low-and-middle-income countries. A systematic review and meta-analysis. Arch Public Health. 2021;79(1):2.

25. Sakeena MHF, Bennett AA, McLachlan AJ. Non-prescription sales of antimicrobial agents at community pharmacies in developing countries: a systematic review. Int J Antimicrob Agents. 2018;52(6):771-82.

26. Torres NF, Chibi B, Middleton LE, Solomon VP, Mashamba-Thompson TP. Evidence of factors influencing self-medication with antibiotics in low and middle-income countries: a systematic scoping review. Public Health. 2019;168:92-101.

27. Goossens H, Ferech M, Vander Stichele R, Elseviers M. Outpatient antibiotic use in Europe and association with resistance: a cross-national database study. The Lancet. 2005;365(9459):579-87.

28. Peter C, Prema-chandra A, Sanjaya S, Fahad K, John C. Antimicrobial resistance: the major contribution of poor governance and corruption to this growing problem. PLOS ONE. 2015;10(3):e0116746.

29. Sah S, Fugh-Berman A. Physicians under the influence: aocial psychology and industry marketing strategies. J Law Med Ethics. 2013;41(3):665-72.

30. Navarro-San Francisco C, Del Toro MD, Cobo J, De Gea-García JH, Vañó-Galván S, Moreno-Ramos F, et al. Knowledge and perceptions of junior and senior Spanish resident doctors about antibiotic use and resistance: results of a multicenter survey. Enferm Infecc Microbiol Clin. 2013;31(4):199-204.

31. Dimova R, Dimitrova D, Semerdjieva M, Doikov I. Patient attitudes and patterns of self-medication with antibiotics-a cross-sectional study in Bulgaria. Maced J Med Sci. 2015;7(4):655-61. 
32. Askarian M, Maharlouie N. Irrational antibiotic use among secondary school teachers and university faculty members in Shiraz, Iran. Int J Prev Med. 2012;3(12):839-45.

33. Huang Y, Gu J, Zhang M, Ren Z, Yang W, Chen Y, et al. Knowledge, attitude and practice of antibiotics: a questionnaire study among 2500 Chinese students. BMC Med Educ. 2013;13(1):163.

34. Napolitano F, Izzo MT, Di Giuseppe G, Angelillo IF. Public knowledge, attitudes, and experience regarding the use of antibiotics in Italy. PLoS ONE. 2013:8(12):e84177.

35. Siddiqui S, Cheema MS, Ayub R, Shah N, Raza SM. Knowledge, attitudes and practices of parents regarding antibiotic use in children. J Ayub Med Coll Abbottabad. 2014:26(2):170-3.

36. Sun KS, Seongmi M, Jung KE. Public knowledge and attitudes regarding antibiotic use in South Korea. J Korean Acad Nurs. 2011;41(6):742-9.

37. Lim KK, Teh CC. A cross sectional study of public knowledge and attitude towards antibiotics in Putrajaya, Malaysia. Southern Med Rev. 2012;5(2):26-33.

38. Chan YH, Fan MM, Fok C-M, Lok ZL, Ni M, Sin C-F, et al. Antibiotics nonadherence and knowledge in a community with the world's leading prevalence of antibiotics resistance: implications for public health intervention. Am J Infect Control. 2012;40(2):113-7.

39. Babitsch B, Gohl D, von Lengerke T. Re-revisiting Andersen's behavioral model of health services use: a systematic review of studies from 1998-2011. Psychosoc Med. 2012;9:Dc11.

40. Andersen RM. Revisiting the behavioral model and access to medical care: does it matter? J Health Soc Behav. 1995;36(1):1-10.

41. Raosoft I. Sample size calculation. 2004. http://www.raosoft.com/sampl esize.html.

42. De La Cruz H, D'Urso PA, Ellison A. The relationship between emotional intelligence and successful sales performance in the Puerto Rico market. J Psychol Issues Organ Culture. 2014;5(3):6-39.

43. Amzat I, Raman A. Determining motivators and hygiene factors among excellent teachers in Malaysia: an experience of confirmatory factor analysis. Int J Educ Manag. 2017;31(2):78-97.

44. Nakku VB, Agbola FW, Miles MP, Mahmood A. The interrelationship between SME government support programs, entrepreneurial orientation, and performance: a developing economy perspective. J Small Bus Manage. 2020;58(1):2-31.

45. Abobotain AH, Sheerah HA, Alotaibi FN, Joury AU, Mishiddi RM, Siddiqu $A R$, et al. Socio-demographic determinants of antibiotic misuse in children. A survey from the central region of Saudi Arabia. Saudi Med J. 2013:34(8):832-40.

46. Jasim A. Parental self medication of antibiotics for children in Baghdad city. Int J Pharm Pharm Sci. 2014;6:485-9.

47. Jie $H$, Wang Z. Knowledge, attitudes and perceptions regarding antibiotic use and self-medication: a cross-sectional study among Australian Chinese migrants. Healthc Infect. 2015:20(1):23-8.

48. Yu M, Zhao G, Stålsby Lundborg C, Zhu Y, Zhao Q, Xu B. Knowledge, attitudes, and practices of parents in rural China on the use of antibiotics in children: a cross-sectional study. BMC Infect Dis. 2014;14(1):112.

49. Ling OhA, Hassali MA, Al-Haddad MS, Syed Sulaiman SA, Shafie AA, Awaisu A. Public knowledge and attitudes towards antibiotic usage: a cross-sectional study among the general public in the state of Penang, Malaysia. J Infect Dev Ctries. 2011;5(5):338-47.

50. Harbarth S, Samore MH. Antimicrobial resistance determinants and future control. Emerg Infect Dis. 2005;11(6):794-801.

51. Quan-Cheng K, Jian-Guo W, Xiang-Hua L, Zhen-Zhen L. Inappropriate use of antibiotics in children in China. The Lancet. 2016:387(10025):1273-4.

52. Chang J, Lv B, Zhu S, Yu J, Zhang Y, Ye D, et al. Non-prescription use of antibiotics among children in urban China: a cross-sectional survey of knowledge, attitudes, and practices. Expert Rev Anti Infect Ther. 2018;16(2):163-72.

53. Edwards DJ, Richman PB, Bradley K, Eskin B, Mandell M. Parental use and misuse of antibiotics: are there differences in urban vs. suburban settings? Acad Emerg Med. 2002;9(1):22-6.
54. Alumran A, Yu Hou X, Sun J, Yousef A, Hurst C. The parental use of antibiotics in children in Saudi Arabia. Epidemiol Open Access. 2015. https:// doi.org/10.4172/2161-1165.1000194.

55. Mukattash TL, Alkhatatbeh MJ, Andrawos S, Jarab AS, AbuFarha RK, Nusair MB. Parental self-medication of antibiotics for children in Jordan. J Pharm Health Serv Res. 2020;11(1):75-80.

56. Okumura J, Wakai S, Umenai T. Drug utilisation and self-medication in rural communities in Vietnam. Soc Sci Med. 2002;54(12):1875-86.

57. Radyowijati A, Haak H. Improving antibiotic use in low-income countries: an overview of evidence on determinants. Soc Sci Med. 2003;57(4):733-44.

58. Jodi VE, Ruthanne $M$, et al. Consumer attitudes and use of antibiotics. Emerg Infect Dis. 2003;9(9):1128-35.

59. Huttner B, Goossens H, Verheij T, Harbarth S. Characteristics and outcomes of public campaigns aimed at improving the use of antibiotics in outpatients in high-income countries. Lancet Infect Dis. 2010;10(1):17-31.

60. Wang X, Li S, Li S. Investigation on parents' cognition and behaviors about antibiotics for children (in Chinese). J Mod Med Health. 2014;30(11):1749-50.

61. Sun C, Hu YJ, Wang X, Lu J, Lin L, Zhou X. Influence of leftover antibiotics on self-medication with antibiotics for children: a cross-sectional study from three Chinese provinces. BMJ Open. 2019;9(12):e033679.

62. Chen J, Wang Y, Chen X, Hesketh T. Widespread illegal sales of antibiotics in Chinese pharmacies - a nationwide cross-sectional study. Antimicrob Resist Infect Control. 2020;9(1):12

63. Fang Y. China should curb non-prescription use of antibiotics in the community. BMJ Br Med J. 2014;348:g4233.

64. Wang X, Xuan Z, Storella TH, Zhou X. Determinants of non-prescription antibiotic dispensing in Chinese community pharmacies from socio-ecological and health system perspectives. Soc Sci Med. 2020;256:113035.

65. Mate I, Come CE, Gonçalves MP, Cliff J, Gudo ES. Knowledge, attitudes and practices regarding antibiotic use in Maputo City, Mozambique. PLoS ONE. 2019;14(8):e0221452.

66. Torres NF, Solomon VP, Middleton LE. Identifying the commonly used antibiotics for self-medication in urban Mozambique: a qualitative study. BMJ Open. 2020;10(12):e041323.

67. Roca I, Akova M, Baquero F, Carlet J, Cavaleri M, Coenen S, et al. The globa threat of antimicrobial resistance: science for intervention. New Microbes New Infect. 2015;6:22-9.

68. Al-Dossari K. Parental knowledge, attitude and practice on antibiotic use for Upper Respiratory Tract Infections in children. Majmaah J Health Sci. 2013;1(1):33-45.

69. Panagakou SG, Spyridis N, Papaevangelou V, Theodoridou KM, Goutziana GP, Theodoridou MN, et al. Antibiotic use for upper respiratory tract infections in children: a cross-sectional survey of knowledge, attitudes, and practices (KAP) of parents in Greece. BMC Pediatr. 2011;11(1):60.

70. Zyoud SEH, Taha AA, Araj KF, Abahri IA, Sawalha AF, Sweileh WM, et al. Parental knowledge, attitudes and practices regarding antibiotic use for acute upper respiratory tract infections in children: a cross-sectional study in Palestine. BMC Pediatr. 2015;15:176.

71. Eldalo A, El-Hadiyah T, Yousif M. Sudanese parents'knowledge, attitudes and practice about self-medication to their children: qualitative study. Saudi J Health Sci. 2013:2(2):103-7.

72. Alumran A, Hou X-Y, Hurst C. Assessing the overuse of antibiotics in children in Saudi Arabia: validation of the parental perception on antibiotics scale (PAPA scale). Health Qual Life Outcomes. 2013;11(1):39.

73. Wu J, Yang F, Yang H, Zhang G, Mu K, Feng J, et al. Prevalence of antibiotic self-medication behavior and related factors among children aged 0 to 5 years. Expert Rev Anti-Infect Therapy. 2021;19:1157-64 